Invited critical review

\title{
Cardiac biomarker testing in the clinical laboratory: Where do we stand? General overview of the methodology with special emphasis on natriuretic peptides
}

\author{
Aldo Clerico *, Claudio Passino, Maria Franzini, Michele Emdin \\ Scuola Superiore Sant'Anna and Fondazione G. Monasterio CNR - Regione Toscana, Pisa, Italy
}

\section{A R T I C L E I N F O}

\section{Article history}

Received 6 May 2014

Received in revised form 28 May 2014

Accepted 4 June 2014

Available online $\mathrm{xxxx}$

\section{Keywords:}

Natriuretic peptides

Cardiac endocrine function

Troponins

Immunoassay methods

Heart failure

Cardiovascular risk

\begin{abstract}
A B S T R A C T
Diagnosis of heart failure (HF) is not based on a single test, but on a combination of history, physical examination and appropriate investigations. For these reasons, the accuracy of diagnosis by clinical means alone is often inadequate, especially in the early, asymptomatic stages of the HF. Thus, there is an increasing interest in the development of new cardiovascular biomarkers and, consequently, a great number of laboratory tests have recently been proposed for their assay. The aim of this article is to provide a general overview on the biomarkers, recommended by international guidelines, for the diagnosis, risk stratification, and follow-up of patients with HF. Cardiac natriuretic peptides and in particular the B-type related peptides, which are considered to be the first line biomarker for $\mathrm{HF}$ by international guidelines, will be discussed with special emphasis.
\end{abstract}

c) 2014 Elsevier B.V. All rights reserved.

\section{Contents}

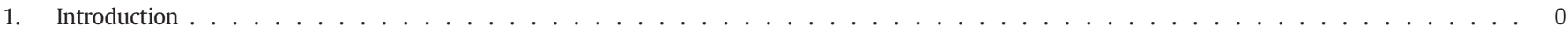

2. The clinical relevance of biochemical biomarkers in heart failure . . . . . . . . . . . . . . . . . . . . . . . . . . . . . . 0

3. The multi-markers $(\mathrm{MM})$ approach to cardiovascular risk evaluation . . . . . . . . . . . . . . . . . . . . . . . . . . 0

4. Cardiac biomarker testing in the clinical laboratory: where we stand . . . . . . . . . . . . . . . . . . . . . . . . . . . . . . . 0

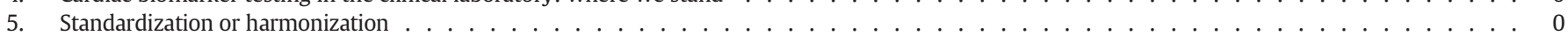

6. The B-type cardiac natriuretic peptide system . . . . . . . . . . . . . . . . . . . . . . . . . . . . . . 0

7. What B-type-related peptide should we measure and why? . . . . . . . . . . . . . . . . . . . . . . . . . . . .

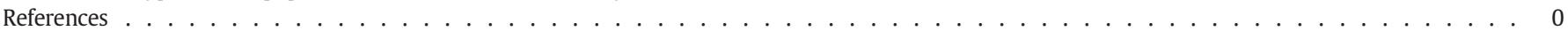

\section{Introduction}

Estimates on the prevalence of symptomatic heart failure (HF) in the general European and North American population range from $0.4 \%$ to $2 \%$ [1-5]; with age, HF incidence and prevalence increase steeply, approaching 1 in 1000 among people over the age of 65 [1-5]. From an economic point of view, compared to other diagnoses and treatments, HF is the primary expenditure in Medicare in the US [4], and in healthcare setting across European countries [1-3].

* Corresponding author at: Dept. of Laboratory Medicine, Fondazione G. Monasterio CNR - Regione Toscana, Via Giuseppe Moruzzi 1, 56124 Pisa, Italy. Tel.: + 390585 493569; fax: + 390585493652 .
Despite the remarkable advances made during the past 50 years in understanding and treating the disease [6,7], HF continues to have a poor prognosis: approximately up to $40 \%$ of patients diagnosed with severe heart failure (NYHA class III-IV or ACC/AHA stage D) in the European and North American population die within one year, with survival rates similar to those of colon cancer, and worse than those of breast or prostate cancer [1-5].

About 20 years ago, Braunwald and Bristow [8] suggested the intriguing hypothesis that it may be possible to reverse the process of HF, which had long been considered to be irreversible and amenable only to palliative therapy. According to this hypothesis, the intrinsic defects in myocardial contraction featured by some patients with chronic HF could be partially reversed by connecting the patient to a ventricular 
assist device for several months [9] and/or using an appropriate pharmacological treatment [8]. In particular, it is now well documented that patients with chronic HF, treated with $\beta$-adrenergic blocking agents, added to background therapy with ACE inhibitors, improve the systolic function and may reverse cardiac remodeling, leading a better clinical outcomes, including prolonged survival and reduced hospitalizations [1-5]. Thus, the view of chronic HF as an irreversible, end-stage process is being replaced by the concept that intrinsic defects of function and structure afflicting the chronically failing heart can be addressed through appropriate therapy [6]. From a theoretical point of view, we can indeed assume that it is easier to arrest or even reverse - a progressive process such as HF if action is taken in the earliest phase of the cardiac alteration.

In order to emphasize both the development and progression of the disease, the ACC/AHA guidelines for the diagnosis and management of chronic HF in the adult recommend a classification of HF based on 4 stages from A to D (Fig. 1) [4]. The first two stages (A and B) do not include symptomatic patients in an attempt to underscore to healthcare providers the importance of an early identification of patients who are at risk for developing HF. In particular, patients in stage A have only risk factors without structural or functional alterations of ventricular myocardial, while those in stage B show cardiac structural (such as hypertrophy) and/or functional (such as impaired left ventricular dysfunction) alterations. The last two stages C and D identify instead symptomatic patients. Since early identification of individuals and risk stratification and diagnosis can be achieved today through the measurement of specific disease or risk markers, an increasing number of new cardiovascular biomarkers have been proposed, as previously reviewed in detail [9-17].

The aim of this review article is to provide a general outline on the methodology of the biomarkers recommended by international guidelines for the diagnosis, risk stratification, and follow-up of patients with HF, with special emphasis on natriuretic peptides, which are considered to be the most useful biomarker for HF.

\section{The clinical relevance of biochemical biomarkers in heart failure}

HF is defined as a syndrome, resulting from any structural or functional cardiac disorder that impairs the ability of the heart to function as a pump to support a physiological circulation [1-5]. The diagnosis of HF is not based on one single test [1,2]. Positive history and some physical signs (such as orthopnea, rales, third heart sound or jugular vein distension) share a good diagnostic specificity, but also a poor sensitivity in diagnosing acute congestive HF (Table 1) [16,17]. Therefore, the diagnosis of both acute and chronic HF relies on clinical judgment based on a combination of history, physical examination and

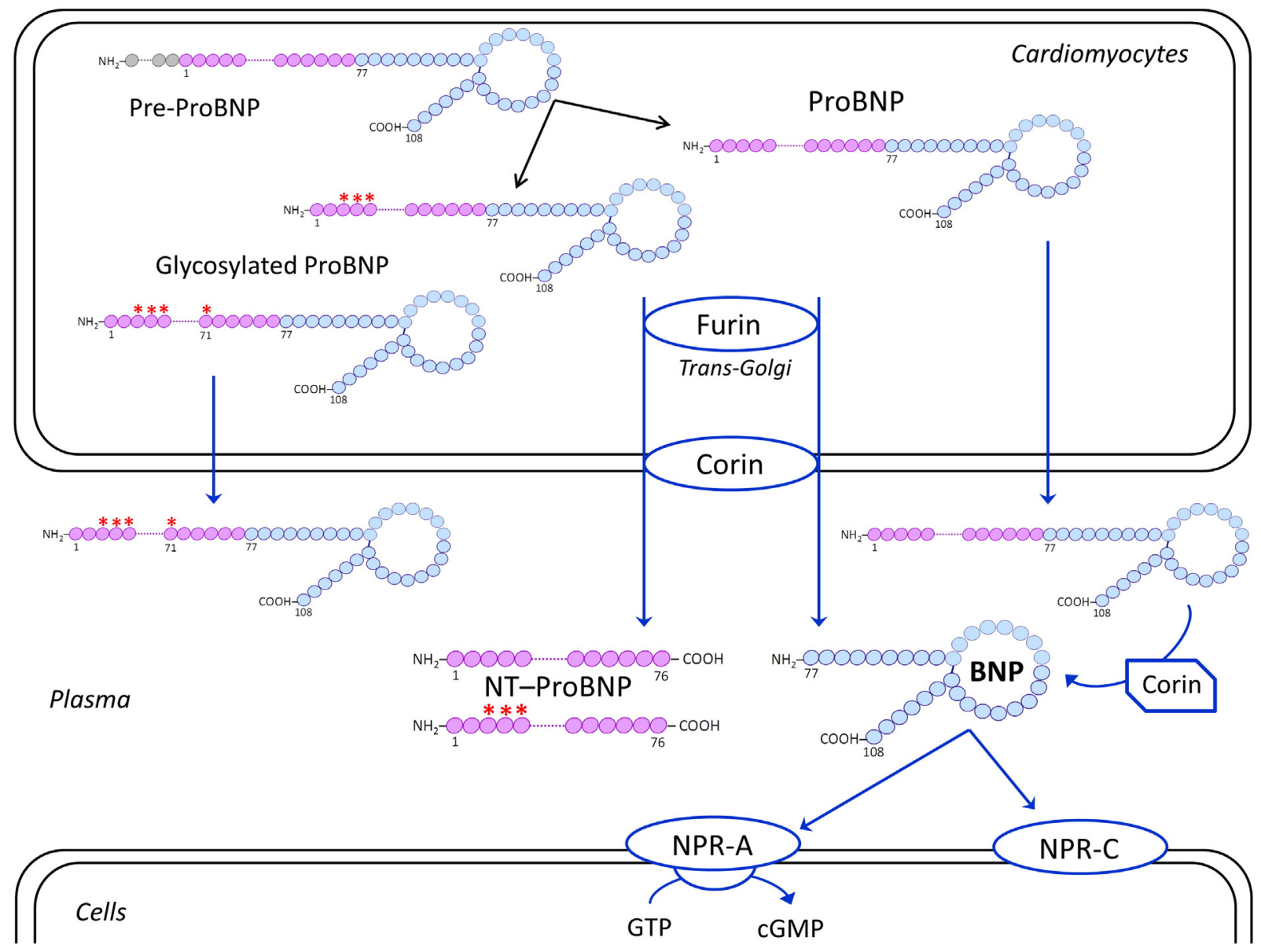

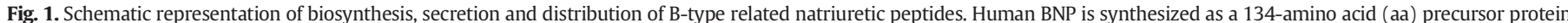

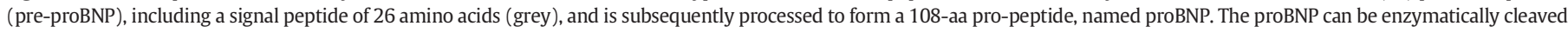

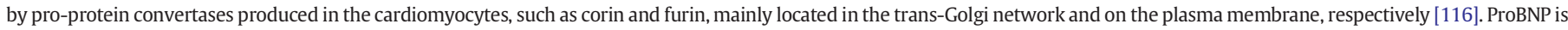

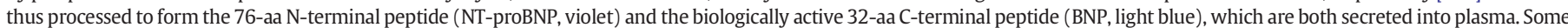

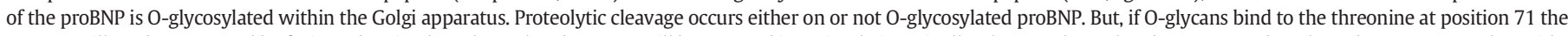

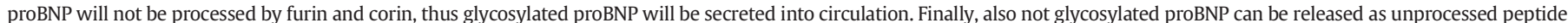

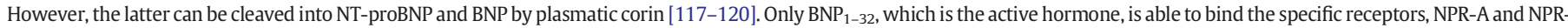

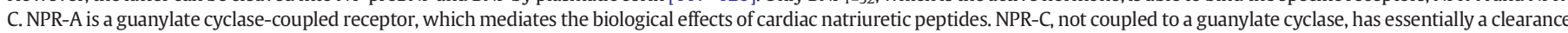
function for all natriuretic peptides. 
Table 1

Accuracy of history and physical findings in diagnosing acute congestive HF (modified from references $[16,17])$.

\begin{tabular}{llll}
\hline Variable & Sensitivity & Specificity & Accuracy \\
\hline History of HF & 62 & 94 & 80 \\
Dyspnea & 56 & 53 & 54 \\
Orthopnea & 47 & 88 & 72 \\
Rales & 56 & 80 & 70 \\
Third heart sound & 20 & 90 & 66 \\
Jugular vein distension & 39 & 94 & 72 \\
Edema & 67 & 68 & 68 \\
\hline
\end{tabular}

appropriate investigations, as recommended by all international guidelines $[1-5,18,19]$.

According to the most recent international guidelines [18,19], natriuretic peptides, and in particular the peptides related to the B-type cardiac peptide hormone (such as BNP and NT-proBNP), are recommended as the first line biomarker for the diagnosis of both acute and chronic HF. The measurement of BNP and NT-proBNP is useful in supporting clinical judgment for the diagnosis or exclusion of HF in the setting of chronic ambulatory HF or acute decompensated HF (with the maximum degree of class of recommendation I and level of evidence A) [19]. The value of natriuretic peptide testing is particularly significant when the etiology of dyspnea is unclear. Indeed, all international guidelines, starting from the first years of this century, state that lower values of BNP or NT-proBNP actually exclude the presence of $\mathrm{HF}$ and higher values have reasonably high positive predictive value to diagnose HF $[1-4,18,19]$.

From a pathophysiological point of view, it is important to underline that the cardiac endocrine function is an essential component of the integrated systems of the body and, thus, plays a pivotal role in fluid, electrolyte and hemodynamic homeostasis [20,21]. A continuous and intense information exchange flows from the endocrine heart system to nervous and immunological systems and to other organs, including the kidney, endocrine glands, liver, adipose tissue, immunocompetent cells, and vice versa. This close link between cardiac natriuretic peptide system and counter-regulatory systems could explain the increase in circulating levels of BNP/NT-proBNP in some noncardiac-related clinical conditions $[20,21]$ (Table 2 ).

As far as the follow-up of HF patients is concerned, BNP and NTproBNP levels mirror the effectiveness of the treatment of acute or

Table 2

Selected causes of elevated natriuretic peptide concentrations (according to references [19-21]).

Cardiac

- Heart failure, including right ventricular syndromes

- Acute coronary syndrome

- Heart muscle disease, including LVH

- Valvular heart disease

- Pericardial disease

- Atrial fibrillation

- Myocarditis

- Cardiac surgery

Cardioversion

Noncardiac

- Advancing age

- Anemia

- Renal failure

- Liver disease

- Pulmonary: obstructive sleep apnea, severe pneumonia, pulmonary hypertension

- Endocrine diseases (such as hyperthyroidism and primitive or secondary

hyperaldosteronism)

- Chronic inflammatory diseases (such as amyloidosis)

- Critical illness

- Bacterial sepsis

- Severe burns

- Toxic-metabolic insults, including cancer chemotherapy and envenomation chronic HF, with lowering of levels over time associated with better clinical outcomes [22,23]. Even if most trials examining the strategy of biomarker "guided" HF management were small and underpowered, at present time, 3 comprehensive meta-analyses concluded that BNPguided therapy reduces all-cause mortality and cardiovascular hospitalization in patients with HF compared with usual clinical care, especially in patients $<75$ years of age with co-morbidities [19,21,22,24-27].

As far as the stratification of cardiovascular risk in HF patients is concerned, measurement of natriuretic peptides is recommended by the most recent guidelines with the maximum degree of evidence (class I and level A) also for the prognosis in HF patient [19]. Several studies have demonstrated that increased circulating levels of cardiac troponin I (cTnI) and T (cTnT) - especially using high-sensitivity methods $[28,29]$ - are found in patients with HF, who often do not present obvious myocardial ischemia or underlying coronary artery disease [30-39]. These findings [30-39] suggest that increased cTnI and cTnT in these patients could be caused by cardiomyocyte injury or necrosis. In chronic or acute decompensated HF, elevated cardiac troponin levels are associated with worse clinical outcomes and mortality. Indeed, HF patients, showing a significant and lasting decrease in troponin levels after appropriate pharmacological treatment have a better prognosis compared to those did not show any or only transient decrease $[31,38]$. Based on these results [30-39], the latest guidelines recommend that troponin I or $\mathrm{T}$ be routinely measured, in addition to natriuretic peptides, in patients presenting with acutely decompensated $\mathrm{HF}$ for evaluating risk stratification, with the maximum degree of evidence (class I and level A) [19].

In addition to natriuretic peptides and troponins, a huge number of other biomarkers have been suggested for the prognostic value in HF; for example, those related to pro-inflammatory mechanisms, oxidative stress, cachexia, neuro-hormonal dysfunction, and myocardial remodeling, as previously reviewed in detail [9-17]. As an example, a list of some of these suggested biochemical biomarkers is reported in Table 3. In particular, several studies have suggested that biomarkers of myocardial fibrosis, such as galectin-3 [40-53] and soluble ST2 [54-64], are predictive of hospitalization and death in patients with HF. Accordingly [40-64], the most recent guidelines [19] also suggest the use of biomarkers of myocardial fibrosis for additive risk stratification, although with a lower degree of evidence compared to natriuretic peptides and troponins, in both ambulatory (class IIb, level B) and acute (class IIb, level A) HF patients. In Table 4, we summarized

Table 3

Suggested prognostic biomarkers for HF.

Neuro-hormones

Natriuretic peptides (ANP, BNP, CNP and related peptides)

Thyroid hormones

Renin-angiotensin-aldosterone system

Catecholamines

Endothelins

Adrenomedullin

Urocortin

Leptin

Adiponectin

Cardiac damage biomarkers

Cardiac troponins, cTnI and cTnT

Remodeling and inflammatory biomarkers

Matrix metalloproteinases (MMPs)

Adhesion molecules (ICAM, VICAM, selectin-P)

C-Reactive Protein (CRP)

Cytokines and related receptor family (IL-2, IL-6, IL-8, TNF- $\alpha$, ST2)

Pentraxin 3

Galectin 3

Oxidative stress molecular biomarkers

Gamma-glumatyltransferases (GGT)

Reactive oxygen species (ROS), Plasma oxidized LDL

Cachexia biomarkers

Alterations of hypophyseal-suprarenal axis

IGF-1 and GH 
Table 4

Pathophysiological and methodological characteristics of biomarkers, which are currently available and recommended by international guidelines [19].

\begin{tabular}{|c|c|c|c|}
\hline Biomarker type & Pathophysiological relevance in HF & $\begin{array}{l}\text { Clinical relevance in } \mathrm{HF} \\
\text { (Level of evidence) }\end{array}$ & Analytical methods \\
\hline ANP and BNP and their related peptides & $\begin{array}{l}\text { Cardiac endocrine response to changes in } \\
\text { hemodynamics, and to neuro-hormonal and } \\
\text { immune systems disturbances }\end{array}$ & $\begin{array}{l}\text { Diagnosis of exclusion of HF (IA) } \\
\text { Prognosis of HF (IA) } \\
\text { Risk stratification (IA) } \\
\text { Follow-up of HF patients (IIA) }\end{array}$ & $\begin{array}{l}\text { Several validated immunoassay methods } \\
\text { using automated platforms }\end{array}$ \\
\hline Cardiac troponins I and $T$ & $\begin{array}{l}\text { Specific marker of injury and damage } \\
\text { of cardiomyocytes }\end{array}$ & Additive risk stratification (IA) & $\begin{array}{l}\text { Several validated immunoassay methods } \\
\text { using automated platforms }\end{array}$ \\
\hline Galectin -3 & $\begin{array}{l}\text { Noncardiac specific biomarker related } \\
\text { to myocardial remodeling and fibrosis }\end{array}$ & Additive risk stratification (IIB) & $\begin{array}{l}\text { Some immunoassay methods using automated } \\
\text { platforms }\end{array}$ \\
\hline sST2 & $\begin{array}{l}\text { Noncardiac specific biomarker related } \\
\text { to myocardial remodeling and fibrosis }\end{array}$ & Additive risk stratification (IIB) & ELISA method \\
\hline
\end{tabular}

some pathophysiological and methodological characteristics of biomarkers, which are currently available and recommended by the most recent international guidelines for HF according to evidence based medicine principles [19].

\section{The multi-markers (MM) approach to cardiovascular risk evaluation}

Based on the knowledge acquired so far, it is likely that HF therapy in the future will rely on strategies that combine multiple biomarkers $[9,13,16]$. This methodological known as the multi-marker (MM) approach or global risk model, is today considered the best model for risk prediction in the individual patient with cardiovascular disease [13,65-67]. Unfortunately, the setup of an adequate MM model is currently complicated by some theoretical and methodological difficulties [68]. According to the MM approach, each biomarker should contribute independently to the diagnostic and prognostic accuracy in a multiple regression model, and ultimately lead to a better outcome for the patient.

In 2010, an expert panel from the American Heart Association established the criteria for the evaluation of novel markers of cardiovascular risk [69]. The panel stated that an adequate evaluation of a novel risk marker should require (i) a sound research design, (ii) a representative at-risk population, and (iii) an adequate number of outcome events. Studies of a novel marker should report the degree to which it adds to the prognostic information provided by standard risk markers. Because no single statistical measure can provide all the information needed to assess a novel marker, studies should also report on measures of both discrimination and accuracy. Furthermore, the clinical value of a marker should be assessed by its effect on patient management and outcomes.

In general, a novel risk marker should be evaluated in several phases according to Evidence-Based Laboratory Medicine principles [70], including initial proof of concept, prospective validation in independent populations, documentation of incremental information when added to standard risk markers, assessment of effects on patient management and outcomes, and ultimately, cost-effectiveness. Biomarkers that do not change the management of a disease are probably unable to significantly affect patient outcome and are thus very seldom cost-effective (judged in terms of quality-adjusted lifeyears gained) $[9,13,71]$. Randomized trials are the gold standard for establishing the effectiveness of biomarker-guided strategies [72]. Unfortunately, there are few examples of such trials in cardiology, particularly in the primary prevention setting [72]. Indeed, the lack of well-designed randomized clinical trials explains the relatively low degree of evidence (i.e., class IIa, level B) assigned to the BNPguided therapy in patients with chronic HF even by the most recent guidelines [19]. However, some pivotal randomized clinical trials on BNP-guided therapy are now in progress $[27,73]$. The results of these studies will hopefully spread more light on the real usefulness of this strategy in HF patients, pushing the adoption of BNP-guided therapy in the management of HF patients.

\section{Cardiac biomarker testing in the clinical laboratory: where we stand}

Cardiovascular biochemical biomarkers are usually measured by means of non-competitive immunometric assay methods, using a combination of two (or more) antisera or monoclonal antibodies specific for separate epitopes of tested biomarkers [9,74]. However, the set-up of a reliable and robust measurement for cardiovascular biomarkers actually presents a very difficult challenger for the experts in laboratory medicine. The desirable characteristics for an "ideal" circulating cardiovascular biomarker, measured by laboratory test, are reported in Table 5.

Cardiovascular biomarkers usually are peptides or proteins (including natriuretic peptides, cardiac troponins, galectin-3 and ST2), which are present in tissues and body fluids at very low concentrations in healthy subjects (i.e., in the range of $\mathrm{ng} / \mathrm{L}$ ). As a result, immunoassay methods with very high analytical sensitivity (i.e., low detection limit, LoD, of about $1 \mathrm{pg} /$ tube or even lower) are necessary to measure with an acceptable analytical imprecision the circulating levels of some cardiac biomarkers (such as troponins and natriuretic peptides) in healthy subjects, especially in pediatric age $[28,29,75-78]$.

Furthermore, some peptide biomarkers (such as BNP) usually share a family of related peptides in vivo and in vitro [21,79-81], while some protein biomarkers (such as troponins) exhibit considerable chemical and structural heterogeneity in blood of both healthy subjects of HF patients [82-84]. These heterogeneous peptides and proteins can differently cross-react with the antibodies used in immunoassay systems, affecting the accuracy of the measurement. As a result, it is not surprising that there are large systematic differences between the circulating

Table 5

Desirable features of an ideal circulating cardiovascular biomarker measured by a laboratory test.

\footnotetext{
- Laboratory test acceptable to patient

- Stability in vivo and in vitro of the biomarker

- Adequate analytical sensitivity (functional sensitivity) of laboratory test

- Good degree in reproducibility and accuracy of laboratory

- Easy to perform

- Complete automation of assay

- International standardization of the laboratory test

- Low cost

- Low biological variation of the biomarker

- Cardiac specificity

- Circulating levels of biomarker closely related to the pathophysiological mechanisms of cardiac disease

- Circulating levels of the biomarker closely related to the therapeutic interventions

- Reference range and cut off values tested for gender, age, and ethnicity dependence

- Diagnostic and prognostic accuracy tested by randomized clinical trials - Cost-benefit ratio favorable tested by randomized clinical trials
} 
levels of biomarkers measured by immunoassay methods for both cTnI [83-85] and BNP [79,86-91].

For example, Wu et al. [92] showed since 1998 that commercial immunoassays generated different results for a given protein concentration due to multiple complex forms of cTnI. According to Apple [93], these data actually demonstrated that it was not possible to compare absolute concentrations obtained with assays from different manufacturers. Commercially available cTnI assays use various standard materials and antibodies with different epitope specificities [83-85]. Hence, troponin I assays may yield results that are unique to a certain method or instrument to the point that values for a same patient sample may differ depending on the assay and platform used $[84,93]$. Due to the heterogeneity between cTnI methods and without an adequate standardization, reference values and decision limits should be determined separately for each method and not be extrapolated from other assays. In terms of clinical practice, this situation is obviously confusing, especially when patients are referred to different laboratories that use different cTnI methods. Starting 2001 a study group began on the behalf of some international organizations (such as AACC and IFCC) a process for standardization of $\mathrm{cTnI}$ immunoassay methods in order to establish a reference measurement procedure and materials [84,95].

\section{Standardization or harmonization}

Standardization of peptide and protein immunoassays, such as cTnI methods, is a very complicated task [95]. A complete standardization approach needs an accepted reference measurement procedures (RPM) and reference materials for the TnI, which however at present are still not available. Indeed, the term standardization can be used only when comparable results among measurement procedures are based on calibration traceability to SI unit using a RMP [83,84,94-96].

After over 10 years of efforts, some Authors think that cTnI assays is unlikely to become standardized [93]. Fred Apple suggests laboratorians and clinicians not get "bogged down" with cTnI standardization, encouraging to aim efforts toward developing a clear understanding of the clinical and analytical evidence for cTnI immunassays and "to be happy" that the technological improvements that have led to the precise detection of low cTnI concentrations also will lead to better patient care [93].

Although we completely agree with Apple that the standardization of some critical immunoassay methods truly appears to be a "mission impossible" [97], we do however believe that achieving better harmonization (i.e., a reduction of heterogeneity) among the results provided by different methods is possible. In particular, we hypothesize that a better understanding of biochemical characteristics and the pathophysiological role of a candidate biomarker may promote a harmonization process indicating to manufacturers and laboratorians specific targets (i.e., epitopes) for the set-up of more accurate immunoassay methods. A good example for a possible harmonization process is represented by immunoassay methods for cardiac B-type-related natriuretic peptide system.

\section{The B-type cardiac natriuretic peptide system}

The human BNP gene encodes for a pre-proBNP molecule of 134 amino acid residue, including a signal peptide of 26 amino acids. BNP is cleaved out of a prohormone molecule of 108 amino acids, the proBNP $_{1-108}$ (proBNP). According to the "classical" scenario of BNP production and secretion from cardiomyocytes, before being secreted from cardiomyocytes into the bloodstream, proBNP is split by some proteolytic enzymes (such as corin and/or furin) into two peptides: the biologically inactive $\mathrm{NH}_{2}$-terminal peptide fragment proBNP $_{1-76}$ (NTproBNP), and the $\mathrm{COOH}$-terminal peptide fragment proBNP $77-108$ [21] (Fig. 1). The latter is a peptide of 32 amino acids $\left(\mathrm{BNP}_{1-32}\right)$ and is usually indicated as BNP. This is the active hormone, that is the only able to bind to the specific natriuretic peptide receptors (named NPR-A, B, C, respectively) [21].

Some recent studies open a new and more complex scenario regarding the pathophysiological and clinical relevance of circulating B-type natriuretic peptides [22]. In addition to the peptide hormone BNP and the inactive peptide NT-proBNP, a huge numbers of circulating proBNP-derived fragments can be identified by chromatographic procedures in human plasma, including the intact and glycosylated forms of the precursor proBNP [98-116] (Fig. 1). Several studies have also demonstrated that intact or glycosylated forms of proBNP constitute a significant portion of immunoreactive B-type-related peptides circulating in plasma of patients with heart failure [98-116]. According to these findings, it is theoretically conceivable that the active hormone (i.e., BNP) may be produced even in vivo from the circulating intact precursor proBNP through enzymatic cleavage by some plasma proteases (such as corin) [117-119]. Indeed, a recent study using an in vivo rat model demonstrated that processing of human proBNP to active BNP can actually occur in the circulation [120]. The peripheral processing of circulating proBNP could likely be submitted to regulatory mechanisms, which might be impaired in patients with heart failure, opening new perspectives in the treatment of heart failure $[80,121]$. Indeed, a novel pharmacological target may be the pharmacodynamic action of drugs inducing and/or modulating the maturation of the prohormone into active hormone (i.e., BNP) [122].

From a methodological and analytical points of view, the large heterogeneity of B-type natriuretic peptides circulating in human blood seems to explain the systematic differences among the results provided by immunoassay methods considered specific to the peptide hormone BNP $[87,90,91,123,124]$. In particular, a recent study, using standard protocols and quality control materials, demonstrated that the IRMA method (by Shionogi's Diagnostic Division, Japan), the ADVIA method for the Centaur platform (by Siemens Health Care Diagnostics) and ST AIA-PACK method for the AIA platform (by TOSOH Corporation, Tokyo, Japan) measured greatly lower (up to the half) BNP values in comparison with other immunoassays, such as the POCT Triage method (by Alere Diagnostics), the BNP Triage Biosite for Access and UniCell DxI platforms (by Beckman Coulter Diagnostics), the MEIA method for the AxSYM platform and the chemiluminescent microparticle immunoassay for ARCHITECT platform (both by Abbotts Diagnostics) [124]. It is interesting to note that the IRMA method by Shionogi, the ADVIA method for Centaur platform, the ST AIA-PACK method (personal communications from TOSOH EUROPE N.V., Tessenderlo, Belgium) use the same antibodies and standard materials supplied by Shionogi's Diagnostic Division [18].

According to the study by Luckenbill et al. [79], a great part of these systematic differences between the different BNP immunoassay systems should be due to the cross-reaction with the glycosylated or not glycosylated proBNP. Liang et al. [98] demonstrated that proBNP constitutes a substantial portion of immunoreactive BNP measured in plasma of HF patients. More recently, Macheret et al. [108], in study using a specific immunoassay method for proBNP [101], demonstrated that this precursor peptide of BNP was detectable in all subjects studied, and its levels were dependent of gender, age, heart rate, and body mass index. Furthermore, these Authors found that the degree of clinical sensitivity and specificity of proBNP assay for the detection of left ventricular dysfunction was comparable to two commercial assays for BNP and NT-proBNP [108]. The results of this study [108] confirm previous reports [101-107] suggesting that the intact precursor of biologically active BNP (i.e., the proBNP) circulates in plasma of both healthy subjects and HF patients.

\section{What B-type-related peptide should we measure and why?}

According to this new scenario regarding the circulating levels of Btype cardiac natriuretic peptides, there are at least 3 different peptides that could be measured in human plasma samples: the active peptide 
hormone, BNP, the inactive N-terminal fragment, NT-proBNP, or the pro-hormone peptide, proBNP $[21,121]$. These 3 peptides have different biochemical characteristics and pathophysiological relevance (Table 6).

From an analytical point of view, the inactive peptide NT-proBNP and proBNP, are more stable in vivo and in vitro, with a longer plasma half-life and a lower intra-individual biological variation, than active peptide BNP (Table 4) $[18,21,81]$. From a pathophysiological point of view, several studies indicate that the inactive peptides, especially proBNP, show an incremental increase of their circulating levels related to progression of HF greater than the active peptide hormone BNP $[102,103,110,115,125]$. In particular, two studies $[115,125]$, which identified and quantified the individual cardiac natriuretic peptides by means of mass spectrometry, reported that the real levels of the peptide hormone $\mathrm{BNP}_{1-32}$ in patients with severe HF are much lower than the BNP concentrations measured by commercially available immunoassay methods. Furthermore, results of another study using mass spectrometry determination actually provide specific evidence for the absence (i.e., concentration below the analytical sensitivity of the measurement) of circulating active peptide $\mathrm{BNP}_{1-32}$ in advanced-stage HF patients [126].

According to the analytical characteristics and clinical results discussed above, we would assume that the inactive peptide NTproBNP and proBNP would be a better biomarker for the progression of HF than the active hormone BNP. However, at present, all the commercially available immunoassay methods considered specific to active peptide BNP significantly cross-react with proBNP [79]. In agreement with these data [79], a recent study [127] has found a good correlation between the BNP and proBNP values measured with commercially available immunoassay methods considered specific for these two peptides in patients with severe HF. Moreover, all the international guidelines state that the commercially available BNP and NT-proBNP immunoassays usually give clinically comparable results when used for diagnosis, prognosis and follow-up of HF patients [18,21,80,88,89,128].

At present, we must realize that the commercially available immunoassay methods considered specific for the active form of Btype cardiac natriuretic peptides present an obvious paradox. From a pathophysiological point of view, it would be better to measure the active peptide BNP (instead of inactive peptide NT-proBNP and proBNP) when we are interested in evaluating the "true biologically active status" of the cardiac endocrine function [21,22]. However, to date, none of the commercially available methods is able to provide such information, accurately, as these methods are greatly affected by inactive peptides the concentrations of which are higher than active hormone in the blood samples of HF patients. In other words, at present time, all the commercially available immunoassay methods for BNP assay are not completely specific for the active form of the peptide.

In conclusion, BNP immunoassay methods show large systematic differences due to the interferences of some inactive peptides, especially the glycosylated and non-glycosylated forms of the precursor peptide, proBNP. The setup of more specific methods for the active peptide $\mathrm{BNP}_{1-32}$ could reduce these systematic differences resulting a better harmonization among results.

\section{Table 6}

Biochemical and physiological characteristics of BNP, NT-proBNP and proBNP peptides.

\begin{tabular}{llll}
\hline & BNP & NT-proBNP & proBNP \\
\hline Molecular mass & $3462 \mathrm{Da}$ & $8457 \mathrm{Da}^{\mathrm{a}}$ & $11900 \mathrm{Da}^{\mathrm{a}}$ \\
Amino acids & 32 & 76 & 108 \\
Biological function & Active hormone & Inactive & Pro-hormone \\
Half life & $15-20$ min & $>60$ min & $>60$ min \\
Glycosylation & Not glycosylated & $\begin{array}{l}\text { Highly glycosylated } \\
\text { in vivo }\end{array}$ & $\begin{array}{l}\text { Highly glycosylated } \\
\text { in vivo }\end{array}$ \\
\end{tabular}

a The molecular mass (MM) of NT-proBNP and proBNP depends to the degree of glycosylation of the peptide; in the Table are reported the MM of not glycosylated peptides.
As a future perspective, a more accurate estimation of both production/secretion of B-type related peptides from cardiomyocytes and overall activity of the cardiac endocrine function could be achieved by the testing plasma samples using simultaneously two methods: one specific for the intact precursor proBNP ${ }_{1-108}$, and the other for active peptide $\mathrm{BNP}_{1-32}[80,121]$. Information obtained by the contemporaneous measurement of proBNP and BNP with specific assays may likely extend our present understanding of pathophysiological mechanisms linking together disease progression and cardiac endocrine dysfunction [80]. However, the clinical usefulness of these new and more specific methods will have to be accurately evaluated by randomized clinical trials in comparison with NT-proBNP and proBNP methods according to the evidence-based medicine principles [69-72].

\section{References}

[1] NICE (National Institute of Clinical Excellence). Clinical Guideline 5. Chronic heart failure. Management of chronic heart failure in adults in primary and secondary care; July 2003 1-44 [London].

[2] Swedberg K, Cleland J, Dargie H, et al. Guidelines for the diagnosis and treatment of chronic heart failure: executive summary (update 2005): The Task Force for the Diagnosis and Treatment of Chronic Heart Failure of the European Society of Cardiology. Eur Heart J 2005;26:1115-40.

[3] Nieminen MS, Böhm M, Cowie MR, et al. Executive summary of the guidelines on the diagnosis and treatment of acute heart failure: the Task Force on Acute Heart Failure of the European Society of Cardiology. Eur Heart J 2005;26:384-416.

[4] Hunt SA, American College of Cardiology, American Heart Association Task Force on Practice Guidelines (Writing Committee to Update the 2001 Guidelines for the Evaluation and Management of Heart Failure). ACC/AHA 2005 guideline update for the diagnosis and management of chronic heart failure in the adult: a report of the American College of Cardiology/American Heart Association Task Force on Practice Guidelines (Writing Committee to Update the 2001 Guidelines for the Evaluation and Management of Heart Failure). J Am Coll Cardiol 2005;46:e1-82.

[5] Adams KF, Lindenfeld J, Arnold JMO, Baker DW, Barnard DH, Baughman KL. Executive summary: HFSA 2006 Comprehensive Heart Failure Practice Guideline. J Card Fail 2006;12:10-38.

[6] Braunwald E, Bristow MR. Congestive heart failure: fifty years of progress. Circulation 2000;102(20 Suppl. 4):IV14-23.

[7] Dipla K, Mattiello JA, Jeevanandam V, Houser SR, Margulies KB. Myocyte recovery after mechanical circulatory support in humans with end-stage heart failure. Circulation 1998;97:2316-22.

[8] Eichhorn EJ, Bristow MR. Medical therapy can improve the biologic properties of the chronically failing heart: a new era in the treatment of heart failure. Circulation 1996;94:2285-96.

[9] Vittorini S, Clerico A. Cardiovascular biomarkers: increasing impact of laboratory medicine in cardiology practice. Clin Chem Lab Med 2008;46:748-63.

[10] Panteghini M. Role and importance of biochemical markers in clinical cardiology. Eur Heart J 2004;25:1187-96.

[11] Macabasco-O'Connell A, Miller PS. Biomarkers for heart failure. Prog Cardiovasc Nurs 2006;21:215-8

[12] De Virginy DR. Novel and potential future biomarkers for assessment of the severity and prognosis of chronic heart faille: a clinical review. Heart Fail Rev 2006; 11:333-4

[13] Vasan S. Biomarkers of cardiovascular disease: molecular basis and practical considerations. Circulation 2006;113:2335-62.

[14] Lainscak M, von Haehling S, Springer J, Anker SD. Biomarkers for chronic heart failure. Heart Fail Monit 2007;5:77-82.

[15] Braunwald E. Biomarkers in heart failure. N Engl J Med 2008;358:2148-59.

[16] Emdin M, Vittorini S, Passino C, Clerico A. Old and new biomarkers of heart failure. Eur J Heart Fail 2009;11:331-5.

[17] Maisel AS, McCullough PA. Cardiac natriuretic peptides: a proteomic window to cardiac function and clinical management. Rev Cardiovasc Med 2003;4(Suppl. 4): S3-S12.

[18] Thygesen K, Mair J, Mueller C, et al. Recommendations for the use of natriuretic peptides in acute cardiac care: a position statement from the Study Group on Biomarkers in Cardiology of the ESC Working Group on Acute Cardiac Care. Eur Heart 2012;33:2001-6.

[19] Yancy CW, Jessup M, Bozkurt B, et al. 2013 ACCF/AHA guideline for the management of heart failure: a report of the American College of Cardiology Foundation/ American Heart Association Task Force on Practice Guidelines. J Am Coll Cardiol 2013;62:e147-239.

[20] Clerico A, Recchia FA, Passino C, Emdin M. Cardiac endocrine function is an essential component of the homeostatic regulation network: physiological and clinical implications. Am J Physiol Heart Circ Physiol 2006;290:H17-29.

[21] Clerico A, Giannoni A, Vittorini S, Passino C. Thirty years of the heart as an endocrine organ: physiological role and clinical utility of cardiac natriuretic hormones. Am J Physiol Heart Circ Physiol 2011;301:H12-20.

[22] Clerico A, Fontana M, Ripoli A, Emdin M. Clinical relevance of BNP measurement in the follow-up of patients with chronic heart failure. Adv Clin Chem 2009;48:163-79. 
[23] Troughton R, Michael Felker G, Januzzi Jr JL. Natriuretic peptide-guided heart failure management. Eur Heart J 2014;35:16-24.

[24] Felker GM, Hasselblad V, Hernandez AF, O'Connor CM. Biomarker-guided therapy in chronic heart failure: a meta-analysis of randomized controlled trials. Am Heart J 2009;158:422-30.

[25] Porapakkham P, Porapakkham P, Zimmet H, Billah B, Krum H. B-type natriuretic peptide-guided heart failure therapy: a meta-analysis. Arch Intern Med 2010;170:507-14.

[26] Troughton RW, Frampton CM, Brunner-La Rocca HP, et al. Effect of B-type natriuretic peptide-guided treatment of chronic heart failure on total mortality and hospitalization: an individual patient meta-analysis. Eur Heart J 2014;35:1559-67.

[27] Januzzi JL, Troughton R. Are serial BNP measurements useful in heart failure management? Serial natriuretic peptide measurements are useful in heart failure management. Circulation 2013;127:500-7.

[28] Clerico A, Giannoni A, Prontera T, Giovannini S. High-sensitivity troponin: a new toll for pathophysiological investigation and clinical practice. Adv Clin Chem 2009;49:1-30.

[29] Apple FS, Collinson PO. Analytical characteristics of high-sensitivity cardiac troponin assay. Clin Chem 2012;58:54-61.

[30] Horwich TB, Patel J, MacLellan WR, et al. Cardiac troponin I is associated with impaired hemodynamics, progressive left ventricular dysfunction, and increased mortality rates in advanced heart failure. Circulation 2003;108:833-8.

[31] Sato Y, Yamada T, Taniguchi R, et al. Persistently increased serum concentrations of cardiac troponin $\mathrm{t}$ in patients with idiopathic dilated cardiomyopathy are predictive of adverse outcomes. Circulation 2001;103:369-74

[32] Setsuta K, Seino Y, Takahashi N, et al. Clinical significance of elevated levels of cardiac troponin $\mathrm{T}$ in patients with chronic heart failure. Am J Cardiol 1999;84:608-11 [A9].

[33] Hudson MP, O'Connor CM, Gattis WA, et al. Implications of elevated cardiac troponin $\mathrm{T}$ in ambulatory patients with heart failure: a prospective analysis. Am Heart 2004; $147: 546-52$

[34] Fonarow GC, Peacock WF, Horwich TB, et al. Usefulness of B-type natriuretic peptide and cardiac troponin levels to predict in-hospital mortality from ADHERE. Am J Cardiol 2008;101:231-7.

[35] Peacock WFIV, De Marco T, Fonarow GC, et al. Cardiac troponin and outcome in acute heart failure. N Engl J Med 2008;358:2117-26.

[36] Ilva T, Lassus J, Siirila-Waris K, et al. Clinical significance of cardiac troponins I and T in acute heart failure. Eur J Heart Fail 2008;10:772-9.

[37] Missov E, Calzolari C, Pau B. Circulating cardiac troponin I in severe congestive heart failure. Circulation 1997:96:2953-8.

[38] Ather S, Hira RS, Shenoy M, et al. Recurrent low-level troponin I elevation is a worse prognostic indicator than occasional injury pattern in patients hospitalized with heart failure. Int J Cardiol 2011;301:H2351-61.

[39] Januzzi Jr JL, Filippatos G, Nieminen M, et al. Troponin elevation in patients with heart failure: on behalf of the third Universal Definition of Myocardial Infarction Global Task Force: heart failure section. Eur Heart J 2012;33:2265-71.

[40] Tang WH, Shrestha K, Shao Z, et al. Usefulness of plasma galectin-3 levels in systolic heart failure to predict renal insufficiency and survival. Am J Cardiol 2011;108:385-90.

[41] de Boer RA, Lok DJ, Jaarsma T, et al. Predictive value of plasma galectin-3 levels in heart failure with reduced and preserved ejection fraction. Ann Med 2011;43:60-8.

[42] Lok DJ, van der Meer P, de la Porte PW, et al. Prognostic value of galectin-3, a novel marker of fibrosis, in patients with chronic heart failure: data from the DEAL-HF study. Clin Res Cardiol 2010;99:323-8.

[43] Shah RV, Chen-Tournoux AA, Picard MH, et al. Galectin-3, cardiac structure and function, and long-term mortality in patients with acutely decompensated heart failure. Eur J Heart Fail 2010;12:826-32.

[44] Felker GM, Fiuzat M, Shaw LK, et al. Galectin-3 in ambulatory patients with heart failure: results from the HF-ACTION study. Circ Heart Fail 2012;5:72-8.

[45] Fermann GJ, Lindsell CJ, Storrow AB, et al. Galectin 3 complements BNP in risk stratification in acute heart failure. Biomarkers 2012;17:706-13.

[46] Lopez-Andrès N, Rossignol P, Iraqi W, et al. Association of galectin-3 and fibrosis markers with long-term cardiovascular outcomes in patients with heart failure left ventricular dysfunction, and dyssynchrony: insights from the CARE-HF (Cardiac Resynchronization in Heart Failure) trial. Eur J Heart Fail 2012;14:74-81.

[47] Anand IS, Rector TS, Kuskowski M, et al. Baseline and serial measurements of galectin-3 in patients with heart failure: relationship to prognosis and effect of treatment with valsartan in the Val-HeFT. Eur J Heart Fail 2013;15:511-8.

[48] Carrasco-Sánchez FJ, Aramburu-Bodas O, Salamanca-Bautista P, et al. Predictive value of serum galectin-3 levels in patients with acute heart failure with preserved ejection fraction. Int J Cardiol 2013;169:177-82.

[49] Chen K, Jiang RJ, Wang CQ et al. Predictive value of plasma galectin-3 in patients with chronic heart failure. Eur Rev Med Pharmacol Sci 2013;17:1005-11.

[50] de Boer RA, Edelmann F, Cohen-Solal A, Mamas MA, Maisel A, Pieske B. Galectin-3 in heart failure with preserved ejection fraction. Eur J Heart Fail 2013;15:1095-101.

[51] Lok DJ, Klip IT, Lok SI, et al. Incremental prognostic power of novel biomarkers (growth-differentiation factor-15, high-sensitivity C-reactive protein, galectin-3, and high-sensitivity troponin-T) in patients with advanced chronic heart failure. Am J Cardiol 2013;112:831-7.

[52] Motiwala SR, Szymonifka J, Belcher A, et al. Serial measurement of galectin-3 in patients with chronic heart failure: results from the ProBNP Outpatient Tailored Chronic Heart Failure Therapy (PROTECT) study. Eur J Heart Fail 2013;15:1157-63.

[53] van der Velde AR, Gullestad L, Ueland T, et al. Prognostic value of changes in galectin-3 levels over time in patients with heart failure: data from CORONA and COACH. Circ Heart Fail 2013;6:219-26.
54] Januzzi Jr JL, Peacock WF, Maisel AS, et al. Measurement of the interleukin family member ST2 in patients with acute dyspnea: results from the PRIDE (Pro-Brain Natriuretic Peptide Investigation of Dyspnea in the Emergency Department) study. J Am Coll Cardiol 2007;50:607-13.

[55] Mueller T, Dieplinger B, Gegenhuber A, Poelz W, Pacher R, Haltmayer M. Increased plasma concentrations of soluble ST2 are predictive for 1-year mortality in patients with acute destabilized heart failure. Clin Chem 2008;54:752-6.

[56] Rehman SU, Mueller T, Januzzi Jr JL. Characteristics of the novel interleukin family biomarker ST2 in patients with acute heart failure. J Am Coll Cardiol 2008;52:1458-65

57] Manzano-Fernandez S, Mueller T, Pascual-Figal D, et al. Usefulness of soluble concentrations of interleukin family member ST2 as predictor of mortality in patients with acutely decompensated heart failure relative to left ventricular ejection fraction. Am J Cardiol 2011;107:259-67.

[58] Aldous SJ, Richards AM, Troughton R, Than M. ST2 has diagnostic and prognostic utility for all-cause mortality and heart failure in patients presenting to the emergency department with chest pain. J Card Fail 2012;18:304-10.

[59] Henry-Okafor Q, Collins SP, Jenkins CA, et al. Soluble ST2 as a diagnostic and prognostic marker for acute heart failure syndromes. Open Biomark J 2012;2012:1-8.

[60] Bayes-Genis A, Zamora E, de Antonio M, et al. Soluble ST2 serum concentration and renal function in heart failure. J Card Fail 2013;19:768-75.

[61] Breidthardt T, Balmelli C, Twerenbold R, et al. Heart failure therapy-induced early ST2 changes may offer long-term therapy guidance. J Card Fail 2013;19:821-8.

[62] Chen LQ, de Lemos JA, Das SR, Ayers CR, Rohatgi A. Soluble ST2 is associated with all-cause and cardiovascular mortality in a population-based cohort: the Dallas Heart Study. Clin Chem 2013;59:536-46.

[63] Wang YC, Yu CC, Chiu FC, et al. Soluble ST2 as a biomarker for detecting stable heart failure with a normal ejection fraction in hypertensive patients. J Card Fail 2013;19:163-8

[64] Gruson D, Lepoutre T, Ahn SA, Rousseau MF. Increased soluble ST2 is a stronger predictor of long-term cardiovascular death than natriuretic peptides in heart failure patients with reduced ejection fraction. Int J Cardiol 2014;172:e250-2.

[65] Kattan MW. Evaluating a new marker's predictive contribution. Clin Cancer Res 2004; 10:822-4

[66] Assmann G, Cullen P, Schulte H. Simple scoring scheme for calculating the risk of acute coronary events based on the 10-year follow-up of the prospective cardiovascular Munster (PROCAM) study. Circulation 2002;105:310-5.

[67] Conroy RM, Pyorala K, Fitzgerald AP, et al. Estimation of ten-year risk of fatal cardiovascular disease in Europe: the SCORE project. Eur Heart J 2003;24:987-1003.

[68] Hense HW. Observations, predictions and decisions - assessing cardiovascular risk assessment. Int J Epidemiol 2004;33:235-9.

[69] Hlatky MA, Greenland P, Arnett DK, et al. Criteria for evaluation of novel markers of cardiovascular risk: a scientific statement from the American Heart Association. Circulation 2009;119:2408-16.

[70] Price PC, Christensen RH. Evidence-based laboratory medicine: principles, practice, and outcome. 2nd ed. Washington DC: AACC Press; 2007 1-545.

[71] Marshall DA, O'Brien BJ. Economic evaluation of diagnostic tests. In: Price PC, Christensen RH, editors. Evidence-based laboratory medicine - from principles to outcomes. Washington DC: AACC Press; 2003. p. 159-86.

[72] Wang TJ. Assessing the role of circulating, genetic, and imaging biomarkers in cardiovascular risk prediction. Circulation 2011;123:551-65.

[73] Guiding Evidence Based Therapy Using Biomarker Intensified Treatment (GUIDEIT). http://clinicaltrials.gov/ct2/show/NCT01685840?term $=$ GUIDE +IT\&rank $=1$ [Accessed September 12, 2012].

[74] Clerico A. The increasing impact of laboratory medicine on clinical cardiology. Clin Chem Lab Med 2003:41:871-83.

[75] Clerico A, Zucchelli GC, Pilo A, Passino C, Emdin M. Clinical relevance of biological variation: the lesson of brain natriuretic peptide (BNP) and NT-proBNP assay. Clin Chem Lab Med 2006;44:366-78.

[76] Clerico A, Fortunato A, Ripoli A, Prontera C, Zucchelli GC, Emdin M. Distribution of plasma cardiac troponin I values in healthy subjects: pathophysiological considerations. Clin Chem Lab Med 2008;46:804-8.

[77] Cantinotti M, Storti S, Parri MS, Prontera C, Murzi B, Clerico A. Reference intervals for brain natriuretic peptide in healthy newborns and infants measured with an automated immunoassay platform. Clin Chem Lab Med 2010;48:697-700.

[78] Giannoni A, Giovannini S, Clerico A. Measurement of circulating concentrations of cardiac troponin I and $\mathrm{T}$ in healthy subjects: a tool for monitoring myocardial tissue renewal? Clin Chem Lab Med 2009;47:1167-77.

[79] Luckenbill KN, Christenson RH, Jaffe AS, et al. Cross-reactivity of BNP, NT-proBNP, and proBNP in commercial BNP and NT-proBNP assays: preliminary observations from the IFCC Committee for Standardization of Markers of Cardiac Damage. Clin Chem 2008;54:619-21.

[80] Clerico A, Vittorini S, Passino C. Measurement of the pro-hormone of brain type natriuretic peptide (proBNP): methodological considerations and pathophysiological relevance. Clin Chem Lab Med 2011;4:1949-54

[81] Goetze JP. Biosynthesis of cardiac natriuretic peptides. Results Probl Cell Differ 2010;50:97-120.

[82] Katrukha AG, Bereznikova AV, Filatov VL, et al. Degradation of cardiac troponin I: implication for reliable immunodetection. Clin Chem 1998;44:2433-40.

[83] Panteghini M. Assay-related issues in the measurement of cardiac troponins. Clin Chim Acta 2009;402:88-93.

[84] Tate JR, Bunk DM, Christenson RH, et al. Standardisation of cardiac troponin I measurement: past and present. Pathology 2010;42:402-8.

[85] Panteghini M, Pagani F, Yeo KT, et al. Evaluation of imprecision for cardiac troponin assays at low-range concentrations. Clin Chem 2004;50:327-32. 
[86] Clerico A, Del Ry S, Giannessi D. Measurement of natriuretic cardiac hormones (ANP, BNP, and related peptides) in clinical practice: the need for a new generation of immunoassay methods. Clin Chem 2000;46:1529-34.

[87] Rawlins ML, Owen WE, Roberts WL. Performance characteristics of four automated natriuretic peptide assays. Am J Clin Pathol 2005;123:439-45.

[88] Apple FS, Panteghini M, Ravkilde J, et al. Quality specifications for B-type natriuretic peptide assays. Clin Chem 2005;51:486-93.

[89] Apple FS, Wu AH, Jaffe AS, et al. National Academy of Clinical Biochemistry and IFCC Committee for Standardization of Markers of Cardiac Damage Laboratory Medicine practice guidelines: analytical issues for biomarkers of heart failure. Circulation 2007; 116:e95-8.

[90] Prontera C, Zaninotto M, Giovannini S, et al. Proficiency testing project for brain natriuretic peptide (BNP) and the N-terminal part of the propeptide of BNP (NTproBNP) immunoassays: the CardioOrmoCheck study. Clin Chem Lab Med 2009;47:762-8.

[91] Clerico A, Zaninotto M, Prontera C, et al. State of the art of BNP and NT-proBNP immunoassays: the CardioOrmoCheck study. Clin Chim Acta 2012;414:112-9.

[92] Wu AHB, Feng YJ, Moore R, et al. Characterization of cardiac troponin subunit release into serum after acute myocardial infarction and comparison of assays for troponin T and I. Clin Chem 1998;44:1198-208.

[93] Apple FS. Standardization of cardiac troponin I assays will not occur in my lifetime. Clin Chem 2012;58:169-71.

[94] Christenson RH, Duh SH, Apple FS, et al. Standardization of cardiac troponin I assays: round robin of ten candidate reference materials. Clin Chem 2001;47:431-7.

[95] Christenson RH, Bunk DM, Schimmel H, Tate JR, IFCC Working Group on Standardization of Troponin I. Point: put simply, standardization of cardiac troponin I is complicated. Clin Chem 2012;58:165-8.

[96] Gantzer ML, Miller WG. Harmonization of measurement procedures: how do we get it done? Clin Biochem Rev 2012;33:95-100.

[97] Iervasi G, Clerico A. Harmonization of free thyroid hormone test: a mission impossible? Clin Chem Lab Med 2011;49:43-8.

[98] Liang F, O'Rear J, Schellenberger U, et al. Evidence for functional heterogeneity of circulating B-type natriuretic peptide. J Am Coll Cardiol 2007;49:1071-8.

[99] Goetze JP. Biochemistry of pro-B-type natriuretic peptide-derived peptides: the endocrine heart revisited. Clin Chem 2004;49:1503-10.

[100] Goetze JP. ProBNP-derived peptides in cardiac disease. Scand J Clin Lab Invest 2004;64:497-510.

[101] Giuliani I, Rieunier F, Larue C, et al. Assay for measurement of intact B-type natriuretic peptide prohormone in blood. Clin Chem 2006;52:1054-61.

[102] Seferian KR, Tamm NN, Semenov AG, et al. The brain natriuretic peptide (BNP) precursor is the major immunoreactive form of BNP in patients with heart failure. Clin Chem 2007;53:866-73.

[103] Hammerer-Lercher A, Halfinger B, Sarg B, et al. Analysis of circulating forms of proBNP and NT-proBNP in patients with severe heart failure. Clin Chem 2008;54:858-65.

[104] Goetze JP, Rehfeld JF. Peptide hormones and their prohormones as biomarkers. Biomark Med 2009;3:335-8.

[105] Dries DJ, Ky B, Wu A, Rame JE, Putt M, Cappola T. Simultaneous assessment of unprocessed ProBNP 1-108 in addition to processed BNP32 improves risk stratification in ambulatory patients with systolic heart failure. Circ Heart Fail 2010;3:220-7.

[106] Goetze JP, Kastrup J, Rehfeld JF. The paradox of increased natriuretic hormones in congestive heart failure patients: does the endocrine heart also fail in heart failure? Eur Heart J 2003;24:1471-2.

[107] Goetze JP, Kastrup J, Pedersen F, Rehfeld JF. Quantification of pro-B-type natriuretic peptide and its products in human plasma by use of an analysis independent of precursor processing. Clin Chem 2002;48:1035-42.
[108] Macheret F, Boerrigter G, McKie P, et al. Pro-B-type natriuretic peptide 1-108 circulates in the general community: plasma determinants and detection of left ventricular systolic dysfunction. J Am Coll Cardiol 2011;57:1386-95.

[109] Shimizu H, Masuta K, Aono K, et al. Molecular forms of human brain natriuretic peptide in plasma. Clin Chim Acta 2002;316:129-35.

[110] Shimizu H, Masuta K, Asada H, Sugita K, Sairenji T. Characterization of molecular forms of probrain natriuretic peptide in human plasma. Clin Chim Acta 2003;334:233-9.

[111] Schellenberger U, O'Rear J, Guzzetta A, Jue RA, Protter AA, Pollitt NS. The precursor to B-type natriuretic peptide is an O-linked glycoprotein. Arch Biochem Biophys 2006;451:160-6.

[112] Seferian KR, Tamm NN, Semenov AG, et al. Immunodetection of glycosylated NTproBNP circulating in human blood. Clin Chem 2008;54:866-73.

[113] Crimmins DL, Kao JL. A glycosylated form of the human cardiac hormone pro Btype natriuretic peptide is an intrinsically unstructured monomeric protein. Arch Biochem Biophys 2008;475:36-41.

[114] Semenov AG, Postnikov AB, Tamm NN, et al. Processing of pro-brain natriuretic peptide is suppressed by $\mathrm{O}$-glycosylation in the region close to the cleavage site. Clin Chem 2009;55:489-98.

[115] Miller WL, Phelps MA, Wood CM, et al. Comparison of mass spectrometry and clinical assay measurements of circulating fragments of B-type natriuretic peptide in patients with chronic heart failure. Circ Heart Fail 2011:4:355-60.

[116] Semenov AG, Tamm NN, Seferian KR, et al. Processing of pro-B-type natriuretic peptide: furin and corin as candidate convertases. Clin Chem 2010;56:1166-76.

[117] Jiang J, Wu S, Wang W, et al. Ectodomain shedding and autocleavage of the cardiac membrane protease corin. J Biol Chem 2011;286:10066-72.

[118] Knappe S, Wu F, Masikat MR, Wu Q. Functional analysis of the transmembrane domain and activation cleavage of human corin: design and characterization of a soluble corin. J Biol Chem 2003;278:52363-70.

[119] Dong N, Chen S, Yang J, et al. Plasma soluble corin in patients with heart failure. Circ Heart Fail 2010;3:207-11.

[120] Semenov AG, Seferian KR, Tamm NN, et al. Human pro-B-type natriuretic peptide is processed in the circulation in a rat model. Clin Chem 2011;57:883-90.

[121] Emdin M, Passino C, Clerico A. Natriuretic peptide assays revisited: do we need proB-type natriuretic peptide? J Am Coll Cardiol 2011;57:1396-8.

[122] Del Ry S, Cabiati M, Clerico A. Recent advances on natriuretic peptide system: new promising therapeutic targets for the treatment of heart failure. Pharmacol Res 2013;76:190-8.

[123] Clerico A, Prontera C, Emdin M, et al. Analytical performance and diagnostic accuracy of immunometric assays for the measurement of plasma BNP and NT-proBNP concentrations. Clin Chem 2005;51:445-7.

[124] Franzini M, Masotti S, Prontera C, et al. Systematic differences between BNP immunoassays: comparison of methods using standard protocols and quality control materials. Clin Chim Acta 2013;424:287-91.

[125] Niederkofler EE, Kiernan UA, O'Rear J, et al. Detection of endogenous B-type natriuretic peptide at very low concentrations in patients with heart failure. Circ Heart Fail 2008;1:258-64.

[126] Hawkridge AM, Heublein DM, Bergen III HR, Cataliotti A, Burnett Jr JC, Muddiman DC. Quantitative mass spectral evidence for the absence of circulating brain natriuretic peptide (BNP-32) in severe human heart failure. Proc Natl Acad Sci U S A 2005;102:17442-7.

[127] Miller WL, Grill DE, Jaffe AS. Comparison of novel pro-BNP1-108 and standard BNP assays in heart failure patients. Clin Chim Acta 2012;413:920-6.

[128] Emdin E, Clerico A, Clemenza F, et al. Consensus document. Recommendations for the clinical use of cardiac natriuretic peptides. J Cardiovasc Med (Ital Heart J) 2005;6:430-46. 